\title{
Uptake of medical devices approved by NICE
}

\author{
Gillian Leng, ${ }^{1}$ Sarah Williams, ${ }^{1}$ Isaac Hung, ${ }^{2}$ Gemma Partridge, ${ }^{1}$ \\ Sonali Sanghvi ${ }^{1}$
}

\begin{abstract}
National Institute for Health and Care Excellence, London, UK ${ }^{2}$ Harvard Global Health Institute, Harvard University, Cambridge, Massachusetts, USA
\end{abstract}

\section{Correspondence to} Dr Sarah Williams, National Institute for Health and Care Excellence, London M1 4BT, UK; sarah.williams122@nhs.net

Received 19 January 2018 Revised 14 March 2018 Accepted 16 July 2018 Published Online First 29 August 2018

\section{Check for updates}

(c) Author(s) (or their employer(s)) 2018. No commercial re-use. See rights and permissions. Published by BMJ.

To cite: Leng G, Williams S, Hung I, et al. BMJ Innov 2018;4:178-184.

\begin{abstract}
Background The UK is sometimes considered to be slow in adopting new technologies. The recent Accelerated Access Review examined adoption challenges and identified opportunities for improvements. This study aims to determine the rate of uptake of selected new medical devices approved by the National Institute for Health and Care Excellence over a 10-year period, and to consider what factors may have influenced their uptake.
\end{abstract}

Methods The selected devices were approved at least 10 years ago to ensure there was sufficient data to review uptake trends. The devices that met the selection criteria were drug-eluting coronary artery stents, the brush used in liquidbased cytology, and fluid-filled thermal balloon and microwave endometrial ablation. Data on uptake were collected from the National Audit of Percutaneous Coronary Interventions (drugeluting stents), the national cervical screening programme (liquid-based cytology) and Hospital Episode Statistics (endometrial ablation).

Results The technologies illustrated different uptake scenarios. Liquid-based cytology showed rapid and complete uptake, probably because it was a nationally driven programme. Neither drug-eluting stents nor endometrial ablation technologies were part of a national programme, and their uptake was slower. The uptake of stents has gradually increased to $88.5 \%$ of percutaneous coronary intervention procedures in the most recent data. For both fluid-filled thermal balloon and microwave ablation, there was an increase and then decline in uptake as other technologies were developed.

Conclusions The data show excellent uptake when promoted through a nationally managed programme. Uptake was slower when left to local systems. Obtaining good, reliable data about the use of medical devices in the National Health Service (NHS) is challenging-collecting real-world data linked to electronic patient records would allow us to better track the impact of new technologies in the future. More robust implementation plans may also increase the uptake rate of cost-effective and potentially life-saving technologies into the NHS.

\section{INTRODUCTION}

The process of innovation in healthcare can be complex, ${ }^{1}$ and the UK is sometimes considered to be slow in adopting resultant new technologies. ${ }^{2}$ Speeding up this process will give patients earlier access to life-changing technologies, and potentially improve efficiency and value in the National Health Service (NHS). ${ }^{3}$ The recently published Accelerated Access Review acknowledges these adoption challenges, yet also recognises opportunities for identifying and more rapidly pulling transformative innovations into the NHS to improve patient outcomes. ${ }^{3}$

The National Institute for Health and Care Excellence (NICE) makes recommendations about the use of healthcare technologies to the NHS, based on a review of clinical and economic evidence. This includes medicines, medical devices, diagnostic techniques, surgical procedures and health promotion activities. ${ }^{4}$ The NHS is legally obliged to fund approved medicines, ${ }^{4}$ but there is no mandate to encourage the uptake of other technologies.

The uptake of selected NICE-recommended drugs is assessed as part of the Innovation Scorecard, published regularly by NHS Digital. ${ }^{5}$ Measurement of the uptake of medical technologies is much more limited, ${ }^{5}$ and it has received less focus, despite the potential for medical technologies to transform healthcare.

The aim of this paper is to determine the rate of uptake of medical devices approved by NICE at least 10 years ago and to consider what factors might have influenced their uptake. 
Table 1 Selected technology appraisals

\begin{tabular}{|c|c|}
\hline Technology appraisal & Description \\
\hline $\begin{array}{l}\text { TA69 Guidance on the use of liquid-based } \\
\text { cytology for cervical screening (published } \\
\text { 2003) }\end{array}$ & $\begin{array}{l}\text { Recommended the use of liquid-based cytology as the primary means of processing samples in the } \\
\text { cervical screening programme in England and Wales, with the brush that makes liquid-based possible } \\
\text { being the medical device investigated }\end{array}$ \\
\hline $\begin{array}{l}\text { TA71 Guidance on the use of coronary artery } \\
\text { stents (published 2003) }\end{array}$ & $\begin{array}{l}\text { Recommended the use of stents where percutaneous coronary intervention is the clinically appropriate } \\
\text { procedure for patients with either stable or unstable angina or with acute myocardial infarction. This was } \\
\text { a review of previous guidance on bare metal stents and an appraisal of drug-eluting stents. A further } \\
\text { appraisal was published in } 2008 \text {, providing further guidance on the circumstances when a drug-eluting } \\
\text { stent should be used. }{ }^{17} \text { Drug-eluting stents are the specific device being investigated }\end{array}$ \\
\hline $\begin{array}{l}\text { TA78 Fluid-filled thermal balloon and } \\
\text { microwave endometrial ablation techniques for } \\
\text { heavy menstrual bleeding (published 2004) }\end{array}$ & $\begin{array}{l}\text { Recommended the use of fluid-filled thermal balloon endometrial ablation and microwave endometrial } \\
\text { ablation as treatment options for women with heavy menstrual bleeding in cases where it has been } \\
\text { decided, by the woman and the clinician responsible for her treatment, that surgical intervention is } \\
\text { appropriate for the management of the condition. The specific devices being investigated are those that } \\
\text { make fluid-filled thermal balloon and microwave endometrial ablation techniques possible }\end{array}$ \\
\hline
\end{tabular}

\section{METHODS}

\section{Criteria for selecting technologies}

There were 482 technology appraisals published on the NICE website between 1 March 2000 and 31 October $2017 .{ }^{6}$ The following criteria were applied to identify relevant appraisals for medical devices that were recommended for use by receiving a positive appraisal:

- Publication in the first 7 years, to ensure there was at least 10 years of data to review trends in uptake. Between 1 March 2000 and 31 July 2007, there were 52 technology appraisals.

- Appraisal of medical devices, defined by NICE as any instrument, apparatus, appliance, software or other article used specifically for diagnostic or therapeutic purposes. ${ }^{7}$ Of the 52 appraisals, eight fitted this category.

- Devices already widely in use (over 50\% adoption) at the point of the guidance being issued were not considered, as a positive recommendation would have less effect on practice. In addition, devices that had been in use for a long period of time were excluded, for example, electroconvulsive therapy, which has been used since the 1930s. This reduced the number to 6 .

- Devices with only one indication, as meaningful interpretation of uptake data would be difficult with multiple indications. Likewise, classes of devices, such as inhalers, were not considered. This reduced the number of eligible technologies to 3 , and these are in table 1 .

\section{Data sources}

Liquid-based cytology

Data on the uptake of the liquid-based cytology technique were obtained from 2001 to 2008 from the NHS cervical screening programme (NHS cervical screening programme, Young person and adult screening programme, Public Health England Screening, 2008). All cervical screening samples are processed only in laboratories enrolled in the national cervical screening programme. Each laboratory had previously used the smear screening technique and was converted to the liquid-based cytology technique. The national cervical screening programme monitored when laboratories converted, therefore providing a complete and reliable set of data.
Drug-eluting stents

Data on the uptake of drug-eluting stents in percutaneous coronary interventions was taken from the National Audit of Percutaneous Coronary Interventions Annual Report 1 January 2015-31 December $2015 .^{8}$ This audit collected information on all percutaneous coronary intervention procedures in all NHS hospitals and most private hospitals from 2002 to 2015 in the UK. The audit measured the uptake of drug-eluting stents by the percentage of percutaneous coronary intervention cases in England using drugeluting stents. Coming from a national audit, these data are the most reliable and accurate representation of the use of drug-eluting stents in England.

Endometrial ablation

Data on the use of endometrial ablation technology were acquired from the Hospital Episode Statistics using the procedure codes in table 2. ${ }^{9}$ This was for the number of elective finished consultant episodes in England from April 2000 to the end of March 2017 for women aged 18 to 54 with a primary diagnosis of heavy menstrual bleeding. Data were collected for the total number of endometrial ablation procedures, the number of microwave ablation procedures and

Table 2 -Office of Population Censuses and Surveys- 4 procedure codes $^{9}$

\begin{tabular}{lll}
\hline Procedure & Date & OPCS-4 procedure code \\
\hline Endometrial ablation & 1 April 2000 to & Q16 or Q17 \\
& 31 March 2016 & \\
Microwave ablation & 1 April 2000 to & Q16.8+Y11.4 or Q17.4+Y11.4 \\
& 31 March 2006 & \\
& 1 April 2006 to & Q16.3 or Q17.6 \\
& 31 March 2017 & \\
& 1 April 2000 to & Q16.8+Y11.8 or Q17.4 \\
& 31 March 2006 & \\
1 April 2006 to & Q16.2+Q17.4 \\
& 31 March 2007 & \\
& 1 April 2007 to & Q16.2+Q17.7 \\
31 March 2017 & \\
\hline
\end{tabular}

OPCS, Office of Population Censuses and Surveys. 


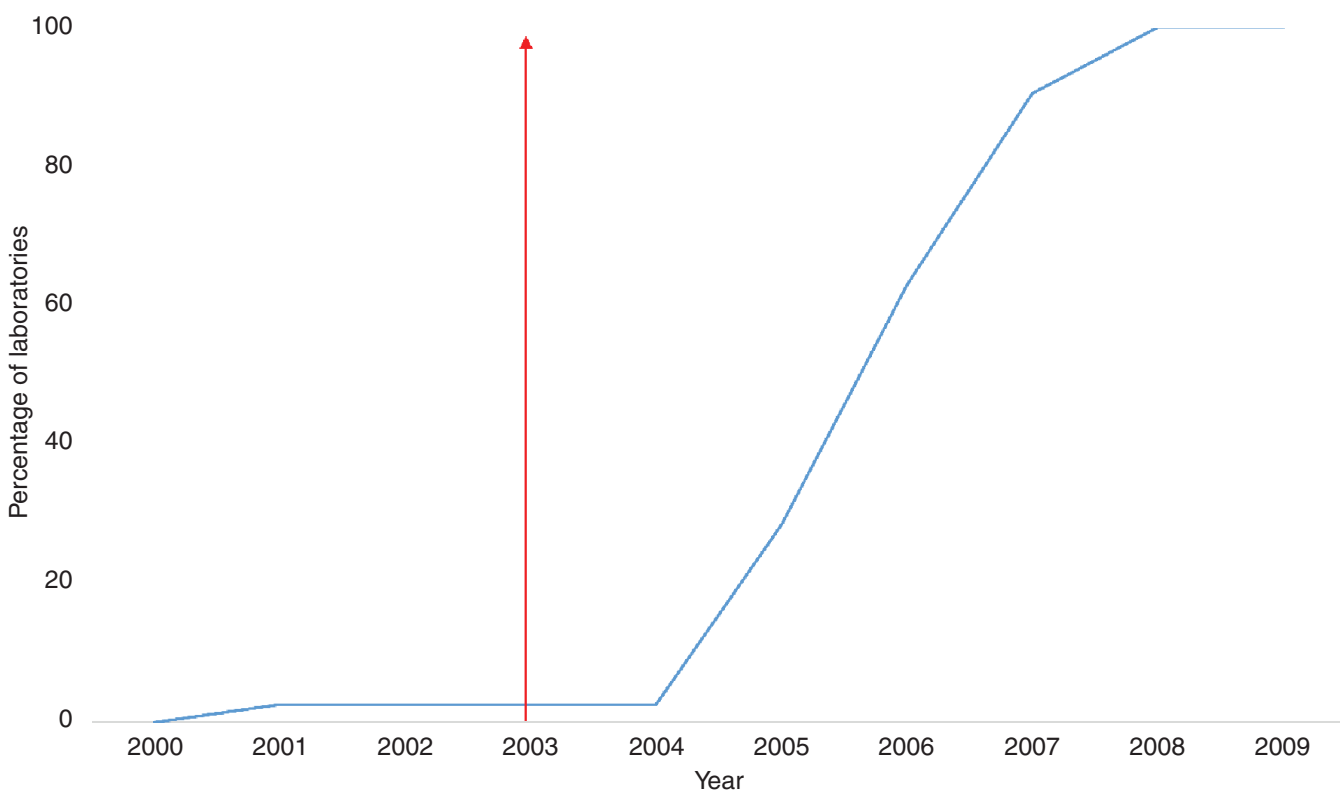

Figure 1 Percentage of laboratories converted to liquid-based cytology technique-National Institute for Health and Care Excellence guidance was published in 2003 (red arrow).

fluid-filled thermal balloon ablation procedures. The uptake was measured by the percentage of total endometrial ablation procedures using microwave ablation or balloon ablation.

Hospital Episode Statistics coding changed in 2006. Before this change, there was some crossover in the coding for endometrial ablation procedures, giving the potential for double counting. To remove the risk of double counting, the subset Q17.4+Y11.4 was removed from the balloon ablation total because this is included under microwave ablation for the same period.

\section{RESULTS}

\section{Uptake of liquid-based cytology}

A total of 134 laboratories in England process cervical screening samples (NHS cervical screening programme, Young person and adult screening programme, Public Health England Screening, 2008). Data on when laboratories converted from processing cervical smears to only liquid-based cytology were available for 116 laboratories. The 18 laboratories for which data were not available were excluded from the calculations. Figure 1 shows liquid-based cytology uptake as measured by the number of individual laboratories only processing liquid-based cytology.

Liquid-based cytology was first introduced in 2001 with three laboratories processing liquid-based cytology as a pilot phase run by the national cervical screening programme. ${ }^{10}$ The conversion to the liquidbased cytology technique led to a rapidly increased rate of uptake between 2004 and 2008 with all laboratories using it by the end of 2008 .

\section{Uptake of drug-eluting stents}

The data showed drug-eluting stents were first used in 2003 and showed a rapid increase in use until 2006. Uptake of drug-eluting stents dropped in 2007 but then subsequently increased, although the rate was slower than pre-2007. The last available data from 2015 showed that drug-eluting stents were being used in $88.5 \%$ of cases of percutaneous coronary intervention. ${ }^{8}$ Figure 2 shows the uptake of drug-eluting stents measured as the percentage of percutaneous coronary intervention cases using drug-eluting stents.

\section{Uptake of fluid-filled thermal balloon and microwave endometrial ablation}

From April 2000 to April 2001, 3 years before NICE guidance was published, $7 \%$ of all endometrial ablation procedures were microwave and 23\% were balloon. ${ }^{9}$ Figure 3 shows the uptake of microwave and thermal-filled balloon techniques as the percentage of all endometrial ablation procedures. Both microwave ablation and balloon ablation procedures increased to their highest level in April 2005 to April 2006 and April 2004 to April 2005 at 30\% and 36\%, respectively. Generally, a higher proportion of endometrial ablation procedures were balloon ablation. Microwave ablation procedures have declined as a proportion of endometrial ablation since then, while a drop in balloon ablation procedures has been quite recent. The total number of endometrial ablation procedures was highest at 14768 in 1 April 2009 to 31 March 2010, and had dropped to 11638 most recently.

\section{DISCUSSION}

This exercise illustrates the challenge of obtaining good, reliable data about the use of medical devices in 


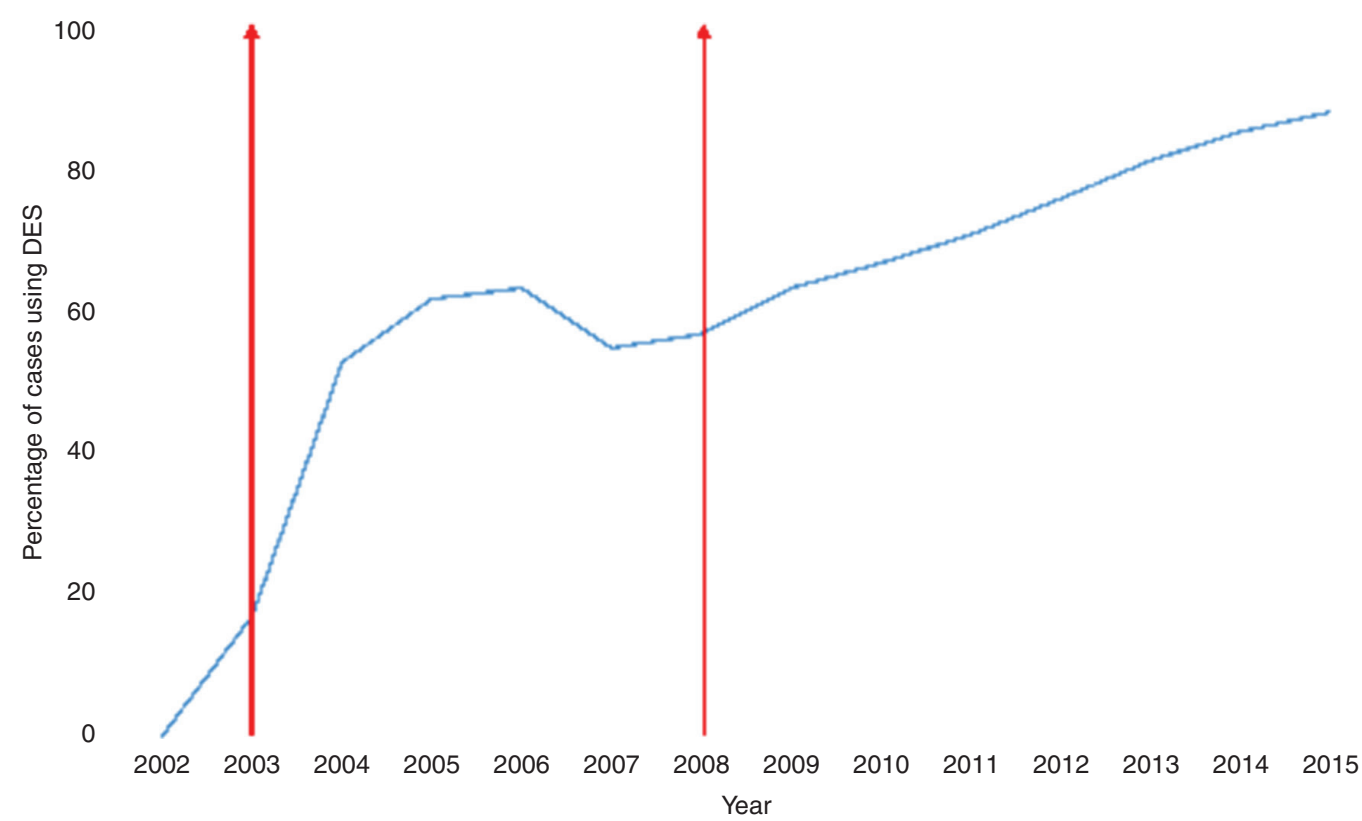

Figure 2 Percentage of percutaneous coronary interventions using drug-eluting stents in a National Health Service setting in England-National Institute for Health and Care Excellence guidance was published in 2003 and 2008 (red arrows). DES, drugeluting stent.

the NHS. As technologies become more digital, often rapidly evolving, it will be important to track both usage and impact on patient outcomes. Some recent initiatives, such as Commissioning Through Evaluation, already link procedures with data collection, ${ }^{11}$ but this needs to become more routine. Future opportunities for collecting real-world data linked to electronic patient records could transform our ability to track the impact of new technologies.

The three technologies covered in this report illustrate three different uptake scenarios. Liquid-based cytology shows rapid and complete uptake, reflecting the effect of being part of a nationally driven scheme. In contrast, neither stents nor endometrial ablation technologies were subject to a national programme, and the resultant uptake was slower. Whereas stents have gradually found a firm place in the treatment of coronary artery disease, the endometrial procedures reflect a pattern of uptake and subsequent decline due to replacement by other technologies, such as impedance-controlled radiofrequency ablation. The scenario of evolving technologies is increasingly common, making it challenging to estimate the likely uptake of specific products.

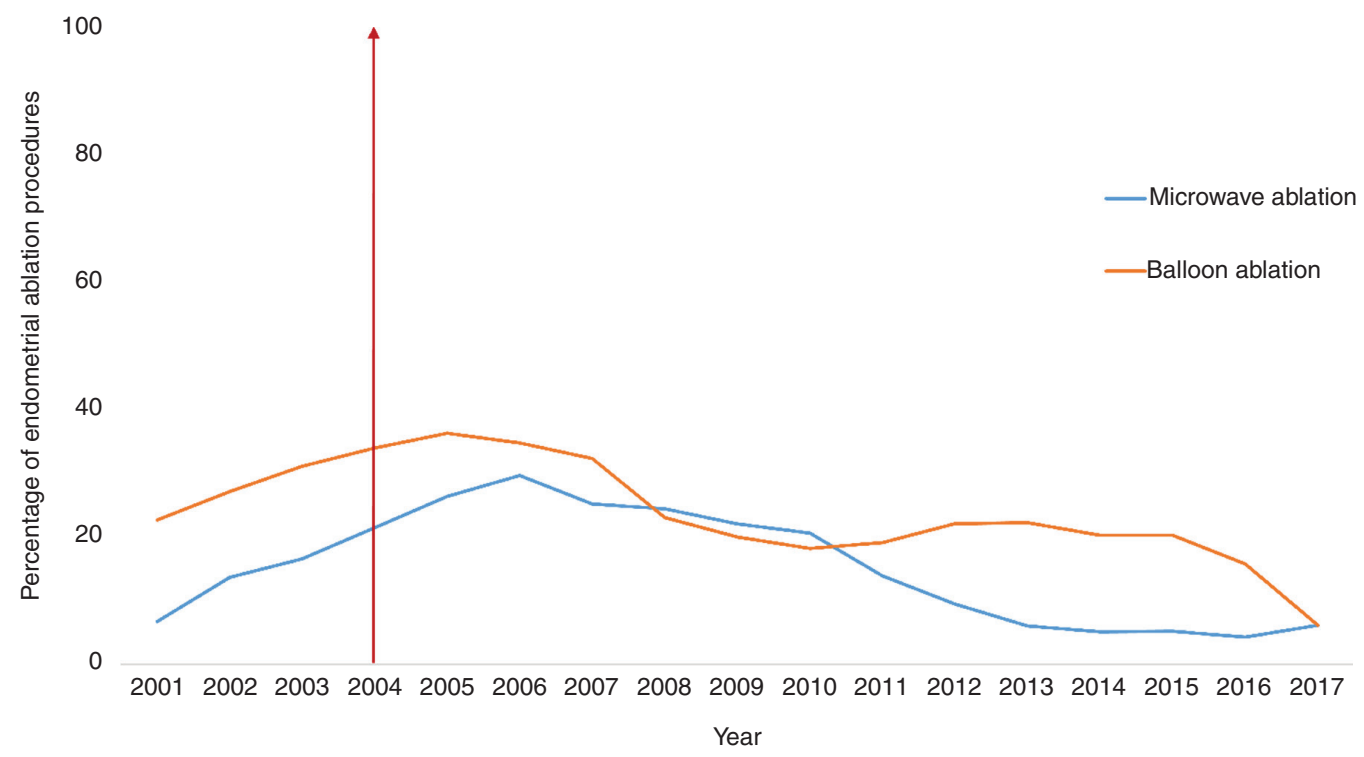

Figure 3 Percentage of endometrial ablation procedures using balloon or microwave ablation procedures-National Institute for Health and Care Excellence guidance was published in 2004 (red arrow). 
There are other factors besides a positive recommendation from NICE that influence the adoption of new technologies. Structure, organisation and financing of the healthcare system are important, and adoption of large-scale innovation may require significant effort. The factors that influence the decision-making process and practice of healthcare professionals are also important. Healthcare professionals may need convincing of the benefits or need of a new technology, and the factors that influence them may differ between specialties. $^{12}$

In general, it appears that the rate of adoption of new technologies is increasing across society as a whole. The traditional telephone took decades to reach $50 \%$ of households in the USA, whereas the mobile phone has taken only 5 years to do the same. ${ }^{13}$ The rate of uptake of healthcare technologies may also be increasing, but more robust implementation plans may increase the uptake rate of cost-effective and potentially life-saving technologies into the NHS.

\section{Liquid-based cytology}

Liquid-based cytology uptake in England increased rapidly and steadily from 2004, and after 4 years, all laboratories were using the technology. The rapid uptake of liquid-based cytology can be attributed to the conversion of laboratories through a nationally managed programme. Had individual laboratories determined if and when to change to liquid-based cytology, then uptake may have been slower.

The NICE guidance recommending the liquid-based cytology technique was published in 2003 and reviewed the pilot study data. A statistically significant decrease in the number of inadequate samples using the technique at the three pilot sites was noted, strengthening the argument for changing to liquid-based cytology. ${ }^{10}$

\section{Drug-eluting stents}

NICE guidance was published in $2003,{ }^{14}$ and the data show an initial increase in uptake of drug-eluting stents between 2003 and 2006. The use dropped to $55 \%$ in 2007, and this may have been a consequence of data presented in 2006 at the World Congress of Cardiology that raised concerns about an increased risk of mortality with drug-eluting stents. ${ }^{15} 16$ Since the drop in uptake in 2007, there has been a continuous increase in the use of drug-eluting stents, with $88.5 \%$ of percutaneous coronary intervention patients in 2015 having the technology.

NICE published further guidance in 2008 on when drug-eluting stents should be used and reviewed some of the safety concerns with them. ${ }^{17}$ The authors of the National Audit of Percutaneous Coronary Interventions felt that the safety issues of drug-eluting stents were now better understood, and that this explained the continuous increase in uptake. ${ }^{18}$ It may also be explained by the availability of second-generation drug-eluting stents, which have better outcomes than first generation. Despite reductions in cost, drugeluting stents remain more expensive than bare metal stents, but have better cost-benefit. ${ }^{81920}$ Drug-eluting stents, however, are not appropriate for every patient and should only be used when the target artery has less than a $3 \mathrm{~mm}$ calibre or the lesion is longer than $15 \mathrm{~mm} .{ }^{17}$ Bare metal stents may be preferred when the patient is at risk of bleeding or needs an urgent operation. ${ }^{8}$ Hence, it will not be possible to have a $100 \%$ uptake of drug-eluting stents in percutaneous coronary interventions.

\section{Fluid-filled thermal balloon and microwave endometrial ablation}

NICE guidance was published in $2004,{ }^{21}$ and the use of thermal balloon ablation peaked shortly after this, and the use of microwave ablation the following year. The use of both thermal balloon and microwave ablation techniques has declined since, with each accounting for approximately $6 \%$ of all endometrial ablation procedures for heavy bleeding from April 2016 to April 2017. ${ }^{9}$

Since the publication of guidance on balloon and microwave endometrial ablation, other secondary ablation procedures have become available. NICE now also recommends impedance-controlled radiofrequency ablation and free fluid thermal endometrial ablation. ${ }^{22}$ There is some evidence that impedance-controlled radiofrequency and microwave ablation may be more effective than other second-generation ablation procedures at increasing rates of amenorrhoea. ${ }^{23}$ The National Heavy Menstrual Bleeding Audit 2014 found that impedance-controlled radiofrequency ablation was the most commonly available secondary ablation procedure, with availability in over $70 \%$ of hospitals. Microwave ablation was only available in $7 \%$ of hospitals in 2013, down from $35 \%$ in $2010,{ }^{24}$ but there are reports of supply problems with this device. ${ }^{23}$ The uptake of fluid-filled balloon and microwave endometrial ablation shows that as other treatment options become available and are recommended, then uptake may drop.

\section{Limitations of the study}

The conclusions of this study are based on the uptake results of four different medical devices. Further lessons may be learnt by examining the uptake of other devices, providing there is an adequate time period to measure the uptake over.

Data on when laboratories converted from processing cervical smears to only liquid-based cytology were missing for 18 laboratories, which were excluded from calculations for uptake. There was no information as to why these laboratories had incomplete data. If there were problems with transferring to the new technology, then the uptake scenario of liquid-based cytology may be different. 


\section{CONCLUSION}

It is important that the recommendation of medical devices by NICE is coupled with support in implementation to ensure patients have timely access to the best quality of care, and that their usage and impact are tracked. The Accelerated Access Review recommends that a pathway for transformative products, including medical devices, should align and coordinate regulatory, reimbursement, evaluation and diffusion processes to bring these products to patients more quickly. ${ }^{3}$ This could be co-ordinated via the collaborative leadership of the Accelerated Access Partnership, of which NICE is a key member, and through the NICE Implementation Collaborative.

A system for tracking the uptake of new medical devices in the NHS would also be beneficial, which can then inform decision-making and implementation strategy for new technologies.

Acknowledgements The authors would like to thank Dominick Moran and Xavier Vaz from the Adoption and Impact team at NICE for their help with collecting the Hospital Episode Statistics data for endometrial ablation procedures, and Janet Rimmer from Young Person and Adult Screening Programmes, Public Health England Screening, for her help with accessing the data on conversion of laboratories to liquid-based cytology technique.

Contributors GL, SW and IH coauthored the manuscript. SW edited and submitted the manuscript. GP and SS were contributing authors to the manuscript.

Funding The authors have not declared a specific grant for this research from any funding agency in the public, commercial or not-for-profit sectors.

Competing interests GL is an executive director of NICE. SW, GP and SS were funded by NICE while they worked on this paper.

Patient consent Not required.

Provenance and peer review Not commissioned; externally peer reviewed.

\section{REFERENCES}

1 World Health Organisation. Barriers to innovation in the field of medical devices (Internet). Geneva. 2010. http://apps.who. int/iris/bitstream/10665/70457/1/WHO_HSS_EHT_DIM_10. 6_eng.pdf (cited 25 Sep 2017).

2 Office for Life Sciences. Life science competiveness indicators (Internet). London. 2016. https://www.gov.uk/government/ uploads/system/uploads/attachment_data/file/523269/BIS-16236-Office-for-Life-Sciences-OLS-life-science-competitivenessindicators-report-May-2016.pdf (cited 25 Sep 2017).

3 Department of Health. Accelerated access review: final report (Internet). London. 2016. https://www.gov.uk/government/ uploads/system/uploads/attachment_data/file/565072/AAR_ final.pdf (cited 25 Sep 2017).

4 National Institute for Health and Care Excellence. Technology appraisal guidance. 2017. https://www.nice.org.uk/About/ What-we-do/Our-Programmes/NICE-guidance/NICEtechnology-appraisal-guidance (cited 1 Sep 2017).

5 NHS Digital. NICE technology appraisals in the NHS in England (Innovation Scorecard): to December 2016. 2017. https://www.digital.nhs.uk/catalogue/PUB30024 (cited 1 Sep 2017).

6 National Institute for Health and Care Excellence. Summary of decisions. 2017. https://www.nice.org.uk/about/what-we-do/ our-programmes/nice-guidance/nice-technology-appraisalguidance/summary-of-decisions (cited 27 Nov 2017).

7 National Institute for Health and Care Excellence. Medical technologies evaluation programme methods guide. 2017 https://www.nice.org.uk/process/pmg33/chapter/introduction (cited 25 Sep 2017).

8 National Institute for Cardiovascular Outcomes Research. National audit of percutaneous coronary interventions annual report 1 January 2015-31 December 2015 (Internet). London. 2017. http://www.ucl.ac.uk/nicor/audits/adultpercutaneous/ reports (cited 01 Oct 2017).

9 Hospital Episode Statistics. Re-used with the permission of health and social care information centre T/A NHS Digital. All rights reserved, 2017.

10 National Institute for Clinical Excellence. Guidance on the use of liquid-based cytology for cervical screening: technology appraisal guidance. NICE technology appraisal guidance 69 . 2003. https://www.nice.org.uk/guidance/ta69 (cited 1 Nov 2017).

11 NHS England. Commissioning through evaluation. https:// www.england.nhs.uk/commissioning/spec-services/npc-crg/ comm-eval/ (cited 4 Dec 2017).

12 Gagnon MP, Sánchez E, Pons JM. From recommendation to action: psychosocial factors influencing physician intention to use Health Technology Assessment (HTA) recommendations. Implement Sci 2006;1:8.

13 McGrath RG. The pace of technology adoption is speeding up. Harvard Business Review. 2013. https://hbr.org/2013/11/ the-pace-of-technology-adoption-is-speeding-up (cited 8 Aug 2017).

14 National Institute for Clinical Excellence. Guidance on the use of coronary artery stents. NICE technology appraisal guidance 71. 2003. https://www.nice.org.uk/guidance/ta71 (cited 1 Nov 2017).

15 Nordmann AJ, Briel M, Bucher HC. Mortality in randomized controlled trials comparing drug-eluting vs. bare metal stents in coronary artery disease: a meta-analysis. Eur Heart $J$ 2006;27:2784-814.

16 Camenzind E, Steg PG, Wijns W. Stent thrombosis late after implantation of first-generation drug-eluting stents: a cause for concern. Circulation 2007;115:1440-55.

17 National Institute for Health and Clinical Excellence. Drugeluting stents for the treatment of coronary artery disease. NICE technology appraisal guidance 152. 2008. https://www. nice.org.uk/guidance/ta152 (cited 1 Sep 2017).

18 National Institute for Cardiovascular Outcomes Research. National audit of percutaneous coronary interventions January 2013-December 2013 (Internet). London. 2014. http://www.ucl. ac.uk/nicor/audits/adultpercutaneous/reports (cited 1 Sep 2017).

19 Baschet L, Bourguignon S, Marque S, et al. Cost-effectiveness of drug-eluting stents versus bare-metal stents in patients undergoing percutaneous coronary intervention. Open Heart 2016;3:e000445.

20 Poder TG, Erraji J, Coulibaly LP, et al. Percutaneous coronary intervention with second-generation drug-eluting stent versus bare-metal stent: systematic review and cost-benefit analysis. PLoS One 2017;12:e177476.

21 National Institute for Clinical Excellence. Fluid-filled thermal balloon and microwave endometrial ablation techniques for heavy menstrual bleeding. NICE technology appraisal guidance 78 . 2004. https://www.nice.org.uk/guidance/ta78 (cited 1 Sep 2017).

22 National Institute for Health and Clinical Excellence. Heavy menstrual bleeding: assessment and management. NICE 
guideline 44. 2007. https://www.ncbi.nlm.nih.gov/books/ NBK56536/ (cited 15 Sep 2017).

23 Daniels JP, Middleton LJ, Champaneria R, et al. Second generation endometrial ablation techniques for heavy menstrual bleeding: network meta-analysis. BMJ 2012;344:e2564.
24 Royal College of Obstetricians and Gynaecologists. National heavy menstrual bleeding audit: final report (Internet). London. 2014. https://www.rcog.org.uk/globalassets/ documents/guidelines/research-audit/national_hmb_audit_ final_report_july_2014.pdf (cited 7 Sep 2017). 